\title{
QT Dispersion and QTc Interval in Patients with Adult Sickle Cell Disease: Electrocardiographic (EKG) and Echocardiographic Evaluation
}

\author{
Taysir S. Garadah ${ }^{1,2}$, Adla B. Hassan1,2, Mohamed Al Alwai1, Ahmed A. Jaradat ${ }^{2}$, \\ Fathia Qurishi' ${ }^{1}$, Abdulla Alajmi ${ }^{1}$ \\ ${ }^{1}$ Salmaniya Medical Complex, Ministry of Health, Manama, Kingdom of Bahrain \\ ${ }^{2}$ Colleges of Medicine and Medical Sciences, Arabian Gulf University, Manama, Kingdom of Bahrain \\ Email: garadaht@hotmail.com
}

Received 5 April 2014; revised 26 April 2014; accepted 10 May 2014

Copyright (C) 2014 by authors and Scientific Research Publishing Inc. This work is licensed under the Creative Commons Attribution International License (CC BY). http://creativecommons.org/licenses/by/4.0/

(c) (i) Open Access

\section{Abstract}

Background: QT dispersion (QTd) varies according to heterogeneity of recovery time in the myocardium, and the impact of iron overload on the QTd in adult patients with Sickle Cell Disease (SCD) is not clear. Aim: This cross-sectional study was designed to evaluate corrected QTc interval and QTd on 12 leads ECG in patients with SCD, and assess the LV systolic and diastolic function using Pulsed Doppler Echocardiogram. Method: All patients were evaluated clinically with pulse Doppler echocardiography. Twelve leads ECG were taken to measure QTd and QTc. Blood samples withdrawn to assess the blood level of ferritin and hemoglobin. Pearson correlation coefficient was used to measure the linear relationship between serum ferritin and QTd. Results: The study included patients with $S C D(n=70$, age $15.7 \pm 8.9$ years), compared with age-matched healthy control group ( $n=70$, age $15.9 \pm 8.9$ years). In patients with SCD compared with healthy control group the QTc (msec) $416 \pm 23.21 \mathrm{~ms}$ vs. $401 \pm 24.12(\mathrm{p}=0.75)$, and the QTd were slightly longer in SCD compared with the control of $43 \pm 22.1$ vs. $38 \pm 20.16 \mathrm{msec},(p=0.071)$ with no significant difference. M mode echo showed that SCD patients compared with control had higher LVMI gm/M ${ }^{2}$ of $105 \pm 10.3$ vs. $83 \pm 7.1, P=0.001$, larger $L V$ end diastolic dimension $(\mathrm{cm})$ of $5.5 \pm 0.32 \mathrm{vs} .4 .72 \pm$ $0.35, \mathrm{p}=0.03, \mathrm{RV}$ diameter $(\mathrm{cm})$ of $2.8 \pm 0.42 \mathrm{vs} .2 .4 \pm 0.31,(\mathrm{p}=0.041)$ and $\mathrm{RV}$ wall thickness $(\mathrm{mm})$ of $0.31 \pm 0.06$ vs. $0.28 \pm 0.03$, $(p=0.024)$. Pulsed Doppler showed high LV transmitral E wave velocity of $85.23 \pm 1.92$ vs. $62.43 \pm 1.67 \mathrm{~m} / \mathrm{s}(\mathrm{p}=0.001)$, A wave $(\mathrm{msec}) 46.26 \pm 4.7 \mathrm{vs} .56 .24 \pm 3.2$ $\mathrm{m} / \mathrm{s}, \mathrm{p}=0.032$, with $E / A$ ratio of $1.86 \pm 0.01$ vs. $1.10 \pm 0.03,(p=0.024)$ and $D T$ of $E$ wave $(\mathrm{msec})$ of $156.43 \pm 23.5$ vs. $189.87 \pm 19.5,(p=0.031)$. Left ventricle ejection fraction percentage was similar between both groups, but SCD had significantly higher right ventricle tricuspid annular plane systolic excursion TAPSE $(\mathrm{cm})$ of $1.23 \pm 0.21 \mathrm{vs.} 1.11 \pm 0.23 \mathrm{~cm}(\mathrm{p}=0.02)$, and the tricuspid valve ve- 
locity showed significant higher velocity $(\mathrm{m} / \mathrm{s})$ in the SCD patients of $2.9 \pm 0.14 \mathrm{vs.} 1.7 \pm 0.09, \mathrm{p}=$ 0.004 indicating higher pulmonary artery pressure with calculated right ventricle systolic pressure of 38.64 vs. $16.56 \mathrm{mmHg}$. Conclusion: SCD patients compared with control have higher but not significant QT dispersion and corrected QT interval with a significantly larger LV mass and LV diastolic filling indices suggestive of restrictive diastolic pattern. These data indicate that LV diastolic abnormalities compromised initially in patients with SCD.

\section{Keywords}

Sickle Cell Anemia, Tissue Doppler, QT Dispersion, Bahrain

\section{Introduction}

Sickle cell disease (SCD) is a hereditary hemolytic anemia characterized by the synthesis of hemoglobin S (HbSS) [1]. It is characterized by recurrent episodes of hemolytic anemia, vaso occlusive crises with the entrapment of red blood corpuscle in the microvasculature system causing hypo-perfusion infarction in many organs leading to multi-organ dysfunction [2]. Sickle-cell disease occurs more commonly among people whose ancestors lived in tropical and sub-tropical sub-Saharan regions where malaria is common. SCD had an incidence in the Arabian Peninsula in the range of $1.2 \%$ - 2.6\% [3] [4].

Cardiac manifestations of SCD patients vary depending on the patterns of evaluation and the populations in the study with different clinical manifestations of SCD according to patients' ethnicity and geographical distribution [5] [6]. The earliest marker of cardiac involvement in children is diastolic dysfunction followed in adulthood by cardiomegaly and pulmonary hypertension with or without heart failure [7] [8].

Pulse Doppler echocardiography is widely used as a noninvasive tool to assess the mitral and tricuspid flow for the assessment of diastolic function [9] [10]. The LV diastolic filling pattern on pulsed Doppler has been classified into normal, restrictive and abnormal relaxation pattern on the basis of relation between the early filling $\mathrm{E}$ wave and the late filling A wave on transmitral diastolic filling velocity [11]. The pattern of abnormal relaxation had low early filling wave (E) and high atrial wave (A) with E/A ratio $<1$ with high deceleration time of $\mathrm{E}$ wave (DT) and the constrictive pattern had a high $\mathrm{E}$ wave, diminished or absent $\mathrm{A}$ wave with $\mathrm{E} / \mathrm{A}$ ratio $>2$ and shortened DT of $<160$ msec [12] [13].

QT, defined as maximum QT interval minus minimum QT interval, was proposed as an index of ventricular recovery times to distinguish myocardium that is homogenous from myocardium that displays non-homogeneity in the repolarization time of myocardium [13]. The normal range of QTd value is $10-70$ msec with mean $29 \pm$ 26 msec in young age [14]. QTd had been shown to increase in a variety of cardiac diseases including acute myocardial infarction (MI), post MI, hypertrophic cardio-myopathy, left ventricle hypertrophy of hypertension, heart failure, idiopathic dilated cardiomyopathy and long QT syndrome indicating general repolarization abnormality in this group of patients [15]-[18]. The prognostic value of QTd had been evaluated in patients with end stage renal disease patients requiring hemodialysis, and in patients with diabetes mellitus [19] [20].

\section{Aim of the Study}

To evaluate the alterations of QT Dispersion and corrected QTc interval in adult patients with sickle cell disease using twelve leads ECG compared with the norm, and to assess LV systolic and diastolic function of both ventricles using pulsed Doppler echocardiogram.

\section{Material and Methods}

\subsection{Study Population}

Seventy adolescent and young adult (14 - 40 years) patients with sickle cell disease (SCD) were enrolled in the study. The study was conducted during the interval from January 2011 to June 2012. Patient selection was consecutive from patients attending the hematology clinic in Salmaniya Medical Complex (SMC). SMC is the main government hospital in Bahrain with a catchment area of 900,000 populations. Those patients were compared 
with 70 healthy patients referred to cardiology OPD for echocardiographic evaluation.

Inclusion criteria were diagnosis of sickle cell disease SCD with homozygous haemoglobin S (HbSS) made by solubility screening test for sickling and haemoglobin electrophoresis. All patients gave an informed consent and the study protocol was approved by the institutional committee.

Patients with SCA were excluded if they have history of recent blood transfusion within three weeks, had hemoglobinopathy other than SCD, history of rheumatic heart disease, adult congenital heart disease, hypertrophic cardiomyopathy, advance renal or hepatic failure. All patients had full history and were examined clinically for blood pressure and pulse, presence of heart murmur or crackles, raised jugular venous pulse, S3 gallop, and ankle edema. Each patient gave a blood sample for the serum level of haemoglobin ( $\mathrm{Hb})$ and serum ferritin.

\section{Twelve Leads ECG}

All patients in the SCD and the control group had 12 leads ECG, the QT interval corrected for Heart rate was performed using Bazett [21] formula in which the K value modified by Shipley [22] (is 0.397 for men and 0.415 for women). The twelve leads ECG recorded on each patient at $25 \mathrm{~mm} / \mathrm{s}$. Three consecutive cycles were measured in each of the chest leads (V1-V6) and from the three values a mean of QT was calculated in chest leads V1-V6. The QT dispersion was defined as the difference between maximum and minimum QT. The methods of measurement were as reported previously by Pye et al. [23].

\subsection{Echocardiographic Evaluation}

Comprehensive echocardiographic pulsed Doppler and tissue Doppler evaluation was performed by Philips e33 echo machine, using $2.5 \mathrm{MHz}$ transducer by the same cardiologist.

The measurement of M mode, 2D, pulsed and tissue Doppler was performed by two technicians unaware of the subject's clinical status and according to the American Society of Echocardiography guidelines. The LV ejection fraction (EF\%) was measured using the biplane Simpson methods [24].

The M mode guided echo used to measure the systolic and end diastolic diameter of LV cavity as well as the septum and posterior wall. The LV mass index was calculated according to formula described by Devereux et al. [25].

Right ventricle diastolic diameter and thickness of the free wall were measured in the apical view; RV systolic function was evaluated from the tricuspid annular plane systolic excursion (TAPSE) [26].

Using pulse Doppler for mitral and tricuspid valve in the apical view with the sample volume at the tip of the leaflet in apical view and the following parameters were measured: the early peak velocity ( $\mathrm{E}$ wave) and the late atrial contraction wave (A wave), E/A ratio and deceleration time of $\mathrm{E}$ wave (DT). The calculation of the pulse and tissue Doppler waves was made as the mean of three beats at end of inspiration and three at the end of expiration.

\subsection{Statistical Analysis}

Data was entered and analyzed using the Statistical Package of Social Sciences (SPSS) version 20. Data are presented as mean \pm S.D. Student-test was used to analyze the differences between the mean variables of $M$ mode for septal wall thickness of LV and RV cavity and wall thickness and LV mass index in the two groups as well as DT of E wave. The QTd and echo Doppler findings were adjusted for Body Surface Area (BSA) in both groups.

Pearson correlation coefficient was used to measure the linear relationship between serum ferritin and QTd. All reported p-values are two tailed and p-value of $<0.05$ was regarded as significant.

\section{Results}

There were 70 patients with sickle cell disease with mean age of 28 years (range 14 - 40), with 54 male (77\%). Table 1 shows the clinical characteristics of the study and the control group.

Patients with SCD compared with the control group had no difference in the age, gender, and systolic blood pressure, but had significantly low diastolic blood pressure and hemoglobin level with higher heart rate. There was significant high level of ferritin in SCD patients.

QTc in SCD was high of $416 \pm 23.21 \mathrm{msec}$ vs. $401 \pm 24.12 \mathrm{msec}$ in the control ( $\mathrm{p}=0.75)$, QTd was slightly longer in SCD compared with the control of $43 \pm 22.1 \mathrm{msec} v s .38 \pm 20.16 \mathrm{msec},(\mathrm{p}=0.06)$. 
Table 2 shows the measurements of M mode and 2D echocardiographic values of right and left ventricle.

Patients with SCD compared with the control, had a significant increment in left ventricle mass index, and right ventricle diameter and wall thickness. There was no significant differences observed between the two groups for the left ventricle ejection fraction percentage, the LV end systolic and end diastolic dimensions but TAPSE was significantly higher indicating right ventricle systolic dysfunction.

Table 3 shows the Pulsed Doppler measurements for diastolic filling velocity in left ventricle. SCD patients compared with control had significantly the higher LV E/A ratio, lower A wave velocity and shorter deceleration time of $\mathrm{E}$ wave.

Table 1. Clinical characteristics of the study population (data presented as the mean \pm S.D.).

\begin{tabular}{cccc}
\hline Characteristics & SCD N = 70 & Control N = 70 & P value \\
Age & $28.52 \pm 9.11$ & $29.74 \pm 8.71$ & 0.64 \\
Male & $54(77 \%)$ & $53(76 \%)$ & 0.76 \\
Heart rate/min & $79 \pm 8$ & $71 \pm 4$ & 0.04 \\
SBP (mmHg) & $128.47 \pm 7.92$ & $124.58 \pm 8.65$ & 0.85 \\
DBP (mmHg) & $65.84 \pm 4.55$ & $75.25 \pm 3.88$ & 0.042 \\
Hemoglobin (g/L) & $9.3 \pm 1.2$ & $13.2 \pm 1.5$ & 0.01 \\
Serum ferritin (ng/ml) & $323.25 \pm 78.23$ & $86.12 \pm 16.34$ & 0.01
\end{tabular}

Abbreviations: SBP: systolic blood pressure; DBP: diastolic blood pressure; SCD: sickle cell disease.

Table 2. The M mode and 2-D echocardiographic data in the study population, the data was presented as the mean value \pm S.D.

\begin{tabular}{cccc}
\hline & SCD N $=70$ & Control N = 70 & P value \\
\hline LVEDD $(\mathrm{cm})$ & $5.51 \pm 0.32$ & $4.72 \pm 0.35$ & 0.36 \\
LVESD (cm) & $3.63 \pm 0.24$ & $3.12 \pm 0.31$ & 0.65 \\
LV mass index & $105 \pm 10.3$ & $83 \pm 7.1$ & 0.001 \\
RV diameter (cm) & $2.8 \pm 0.42$ & $2.4 \pm 0.31$ & 0.043 \\
RV wall thickness (mm) & $0.31 \pm 0.06$ & $0.28 \pm 0.03$ & 0.024 \\
LVEF (percentage) & $58.90 \pm 4.7$ & $61.22 \pm 3.9$ & 0.061 \\
RV TAPSE (mm) & $1.23 \pm 0.21$ & $1.11 \pm 0.23$ & 0.04 \\
\hline
\end{tabular}

Abbreviations: LVEDD: left ventricle end diastolic dimension; LVESD: left ventricle end systolic dimension; EF\%: ejection fraction percentage; TAPES: tricuspid annular plane excursions.

Table 3. Pulsed and tissue Doppler parameters in the study patients (data presented as the mean \pm S.D.).

\begin{tabular}{cccc}
\hline Parameters & SCD & Control & P value \\
\hline LV E wave (msec) & $85.23 \pm 1.92$ & $62.43 \pm 1.67$ & 0.001 \\
LV A wave (msec) & $46.26 \pm 4.7$ & $56.24 \pm 3.2$ & 0.032 \\
LV E/A & $1.86 \pm 0.01$ & $1.10 \pm 0.03$ & 0.024 \\
LVDT of E wave (msec) & $156.43 \pm 23.5$ & $189.87 \pm 19.5$ & 0.031 \\
Tricuspid valve regurgitation velocity (m/sec) & $2.9 \pm 0.14$ & $1.7 \pm 0.09$ & 0.04 \\
\hline
\end{tabular}

Abbreviations: SCD: sickle cell disease; LV: left ventricle; RV: right ventricle; E: pulsed Doppler early diastolic filling; A: atrial diastolic filling; DT: Deceleration time of $\mathrm{E}$ wave. 
The tricuspid valve velocity showed significant higher velocity $(\mathrm{m} / \mathrm{s})$ in the sickle cell disease patients of 2.9 \pm 0.14 vs. $1.7 \pm 0.09$, $p=0.004$ indicating higher pulmonary artery pressure with calculated right ventricle systolic pressure of 38.64 vs. $16.56 \mathrm{mmHg}$.

Out of the 70 patients with SCD, there were 15 (22\%) patients with TVR of $>2.6 \mathrm{~m} / \mathrm{s}$ on continuous wave velocity, three (4\%) of them had TVR $>3 \mathrm{~m} / \mathrm{s}$ and 65 patients had TVR $<2.6 \mathrm{~m} / \mathrm{s}$.

There was weak positive correlation noted between serum level of ferritin QT dispersion $(r=0.35)$. Twenty eight out of 70 (40\%) patients with SCD were consuming hydroxyl urea medication.

\section{Discussion}

In patients with SCD there were a higher heart rate and lower diastolic blood pressure which is in agreement with others reports where chronic hemolytic anemia is accompanied by a state of hyperkinetic circulation and tachycardia [27], and reduced peripheral resistance with an increase of volume chambers with hypertrophy [28].

These ECG findings on QTd may indicate the mild impact of iron deposition in the myocardium in this group of patients and perhaps a long-term follow up for serum ferritin and QT dispersion may be warranted to evaluate the temporal relationship between these two factors. In other studies QTd was significantly increased in patients with coronary artery disease, end stage renal disease and in diabetes mellitus [19] [20].

The ECG finding in this study is in keeping with previous reports indicating that patients with SCD have non-significant increase of QTd compared with controls [29]. However the increase of LV wall thickness and LV mass index in SCD patients in this study may both increase the heterogeneity of repolarization and prolongation of QT dispersion. The significant increment of QTd in SCD patients may be due to early disease involvement.

The prolongation of QT interval is associated with an increased risk of a characteristic life threatening cardiac arrhythmia and hence the increment of QT interval in this study may herald such late outcome [17].

The main findings of SCD compared with controls on echo Doppler of LV filling pattern showed higher early diastolic filling of LV and high E/A ratio suggesting restrictive diastolic pattern and thus stiff LV wall. These findings are in keeping with another study by Yaprak et al. [30] who demonstrated that SCD patients had a significantly higher $\mathrm{E}$ wave, E/A ratio, with lower A wave velocity, suggesting restrictive pattern in $54 \%$ in the study population; no correlation was found with hemoglobin level. Similarly, it has been reported that transmitral diastolic filling measured by Doppler in patients with thalassemia exhibits a restrictive pattern [31]. This was in agreement with a previous report that high E/A ratio is the most common finding in patients with hemolytic anemia [32].

The LVEF\% and fractional shortening were normal with no difference between patients with SCD and the control group. The normal left ventricle systolic function indicates iron overload have very minimal deleterious effect on myocardial systolic function.

In this study, patients with sickle cell disease had dilation LV, RV cavities compared with the control. Moreover they had greater left ventricle mass index and thicker RV wall. The systolic function of left systolic ventricle was preserved with no difference between LVEF percent compared with control. However RV systolic function as assessed by TAPSE showed significant dysfunction than control. It is possible that these parameters of systolic LVEF\% are insensitive due to its load-dependent relationship. It has been observed that patients with SCD had higher preload and lower after-load [33] which cause higher diastolic filling and shorter DT of E which was observed also in our patients. The RV dysfunction in this study may be due to lung involvement with predominant vaso-occlusive effect and the smaller RV mass than the left ventricle resulting in a faster functional derangement.

The diastolic filling pattern for LV was suggestive of restrictive pattern with a significantly high $\mathrm{E}$ wave with shortened deceleration time. This is in keeping with one report where preload increment is associated with increase of early filling and shortened deceleration time [34].

There were 15/70 (22\%) patients in the SCD group who had pulmonary hypertension with TR velocity of > $2.6 \mathrm{~m} / \mathrm{s}$. The incidence of pulmonary artery hypertension of $22 \%$ in this study was lower than others where the incidences range between $33 \%$ - 45\% [35].

The pathogenesis of pulmonary artery hypertension in patients with SCD is multifactorial and may be due to sickling phenomena, vaso-occlusive crisis or acute chest syndrome. The repetitive intravascular hemolysis results in the release of hemoglobin that scavenges nitric oxide which finally leads to acute and chronic pulmonary 
vasoconstriction [36] [37].

The positive correlation between the ferritin and QTd in this study supports the notion that iron overload [37] and dilation of the ventricular chambers are implicated in the pathogenesis of pulmonary hypertension and arrhythmia [38].

\section{Limitation of the Study}

This study was for conducted on adult patients but children and adolescents were excluded and perhaps may invite for missing an important data in term of disease process in patients with SCD.

\section{Conclusion}

SCD patients compared with controls have higher QT dispersion and corrected QT interval with a significantly larger LV mass and LV diastolic filling indices suggestive of restrictive diastolic pattern. These data indicate that LV diastolic abnormalities compromise initially in patients with SCD.

\section{Acknowledgments}

This study was conducted with the support of a grant from the Arabian Gulf University.

\section{References}

[1] Bunn, H.F. (1997) Pathogenesis and Treatment of Sickle Cell Disease. The New England Journal of Medicine, 337, 762-769. http://www.ncbi.nlm.nih.gov/pubmed/9287233 http://dx.doi.org/10.1056/NEJM199709113371107

[2] Platt, O.S., Brambilla, D.J., Rosse, W.F., Milner, P.F., Castro, O., Steinberg, M.H., et al. (1994) Mortality in Sickle Cell Disease. Life Expectancy and Risk Factors for Early Death. The New England Journal of Medicine, 330, 16391644. http://www.ncbi.nlm.nih.gov/pubmed/7993409 http://dx.doi.org/10.1056/NEJM199406093302303

[3] Alhamdan, N.A., Almazrou, Y.Y., Alswaidi, F.M. and Choudhry, A.J. (2007) Premarital Screening for Thalassemia and Sickle Cell Disease in Saudi Arabia. Genetics in Medicine, 9, 372-377.

http://www.ncbi.nlm.nih.gov/pubmed/17575503 http://dx.doi.org/10.1097/GIM.0b013e318065a9e8

[4] Nasserullah, Z., Alshammari, A., Abbas, M.A., Abu-Khamseen, Y., Qadri, M., Jafer, S.A., et al. (2003) Regional Experience with Newborn Screening for Sickle Cell Disease, Other Hemoglobinopathies and G6PD Deficiency. Annals of Saudi Medicine, 23, 354-357. http://www.ncbi.nlm.nih.gov/pubmed/16868367

[5] El-Hazmi, M.A., Warsy, A.S., Al-Swailem, A.R., Al-Swailem, A.M. and Bahakim, H.M. (1996) Sickle Cell Gene in the Population of Saudi Arabia. Hemoglobin, 20,187-198. http://www.ncbi.nlm.nih.gov/pubmed/8854129 http://dx.doi.org/10.3109/03630269609027928

[6] Pearson, H.A. (1999) Reply: Sickle cell disease in the Kingdom of Saudi Arabia: East and West. Annals of Saudi Medicine, 19, 281-282. http://www.ncbi.nlm.nih.gov/pubmed/17283480

[7] Batra, A.S., Acherman, R.J., Wong, W.Y., Wood, J.C., Chan, L.S., Ramicone, E., et al. (2002) Cardiac Abnormalities in Children with Sickle Cell Anemia. American Journal of Hematology, 70, 306-312.

http://www.ncbi.nlm.nih.gov/pubmed/12210812 http://dx.doi.org/10.1002/ajh.10154

[8] Zilberman, M.V., Du, W., Das, S. and Sarnaik, S.A. (2007) Evaluation of Left Ventricular Diastolic Function in Pediatric Sickle Cell Disease Patients. American Journal of Hematology, 82, 433-438. http://www.ncbi.nlm.nih.gov/pubmed/17266053 http://dx.doi.org/10.1002/ajh.20866

[9] Bahl, V.K., Malhotra, O.P., Kumar, D., Agarwal, R., Goswami, K.C., Bajaj, R., et al. (1992) Noninvasive Assessment of Systolic and Diastolic Left Ventricular Function in Patients with Chronic Severe Anemia: A Combined M-Mode, Two-Dimensional, and Doppler Echocardiographic Study. American Heart Journal, 124, 1516-1523. http://www.ncbi.nlm.nih.gov/pubmed/1462908 http://dx.doi.org/10.1016/0002-8703(92)90066-5

[10] Lindqvist, P., Henein, M.Y. and Wikstrom, G. (2009) Right Ventricular Myocardial Velocities and Timing Estimate Pulmonary Artery Systolic Pressure. International Journal of Cardiology, 137, 130-136.

http://www.ncbi.nlm.nih.gov/pubmed/18700177 
http://dx.doi.org/10.1016/j.ijcard.2008.06.043

[11] Choong, C.Y., Herrmann, H.C., Weyman, A.E. and Fifer, M.A. (1987) Preload Dependence of Doppler-Derived Indexes of Left Ventricular Diastolic Function in Humans. Journal of the American College of Cardiology, 10, 800-808. http://www.ncbi.nlm.nih.gov/pubmed/2958532 http://dx.doi.org/10.1016/S0735-1097(87)80273-5

[12] Nishimura, R.A., Schwartz, R.S., Tajik, A.J. and Holmes Jr, D.R. (1993) Noninvasive Measurement of Rate of Left Ventricular Relaxation by Doppler Echocardiography. Validation with Simultaneous Cardiac Catheterization. Circulation, 88, 146-155. http://www.ncbi.nlm.nih.gov/pubmed/8319326 http://dx.doi.org/10.1161/01.CIR.88.1.146

[13] Kautzner, J. and Malik, M. (1997) QT Interval Dispersion and Its Clinical Utility. Pacing and Clinical Electrophysiology, 20, 2625-2640. http://www.ncbi.nlm.nih.gov/pubmed/9358510 http://dx.doi.org/10.1111/j.1540-8159.1997.tb06112.x

[14] Malik, M. and Batchvarov, V.N. (2000) Measurement, Interpretation and Clinical Potential of QT Dispersion. Journal of the American College of Cardiology, 36, 1749-1766. http://www.ncbi.nlm.nih.gov/pubmed/11092641 http://dx.doi.org/10.1016/S0735-1097(00)00962-1

[15] Ashikaga, T., Nishizaki, M., Arita, M., Yamawake, N., Suzuki, M., Hashimoto, Y., et al. (1999) Effect of Dipyridamole on QT Dispersion in Vasospastic Angina Pectoris. American Journal of Cardiology, 84, 807-810.

http://www.ncbi.nlm.nih.gov/pubmed/10513778

http://dx.doi.org/10.1016/S0002-9149(99)00441-5

[16] Galinier, M., Vialette, J.C., Fourcade, J., Cabrol, P., Dongay, B., Massabuau, P., et al. (1998) QT Interval Dispersion as a Predictor of Arrhythmic Events in Congestive Heart Failure. Importance of Aetiology. European Heart Journal, 19, 1054-1062. http://www.ncbi.nlm.nih.gov/pubmed/9717041 http://dx.doi.org/10.1053/euhj.1997.0865

[17] Haverkamp, W., Breithardt, G., Camm, A.J., Janse, M.J., Rosen, M.R., Antzelevitch, C., et al. (2000) The Potential for QT Prolongation and Proarrhythmia by Non-Antiarrhythmic Drugs: Clinical and Regulatory Implications. Report on a Policy Conference of the European Society of Cardiology. European Heart Journal, 21, 1216-1231.

http://www.ncbi.nlm.nih.gov/pubmed/10924311 http://dx.doi.org/10.1053/euhj.2000.2249

[18] Yi, G., Elliott, P., McKenna, W.J., Prasad, K., Sharma, S., Guo, X.H., et al. (1998) QT Dispersion and Risk Factors for Sudden Cardiac Death in Patients with Hypertrophic Cardiomyopathy. American Journal of Cardiology, 82, 15141519. http://www.ncbi.nlm.nih.gov/pubmed/9874057 http://dx.doi.org/10.1016/S0002-9149(98)00696-1

[19] Langen, K.J., Ziegler, D., Weise, F., Piolot, R., Boy, C., Hübinger, A., et al. (1997) Evaluation of QT Interval Length, QT Dispersion and Myocardial M-Iodobenzylguanidine Uptake in Insulin-Dependent Diabetic Patients with and without Autonomic Neuropathy. Clinical Science (London, England: 1979), 93, 325-333. http://www.ncbi.nlm.nih.gov/pubmed/9404224

[20] Wu, V.C., Lin, L.Y. and Wu, K.D. (2005) QT Interval Dispersion in Dialysis Patients. Nephrology, 10, 109-112. http://www.ncbi.nlm.nih.gov/pubmed/15877667 http://dx.doi.org/10.1111/j.1440-1797.2005.00391.x

[21] Bazett, H.C. (1920) The Time Relations of the Blood-Pressure Changes after Excision of the Adrenal Glands, with Some Observations on Blood Volume Changes. The Journal of Physiology, 53, 320-339. http://www.ncbi.nlm.nih.gov/pubmed/16993419

[22] Shipley, R.A. and Hallaran, W.R. (1936) The Four-Lead Electrocardiogram in Two Hundred Normal Men and Women. American Heart Journal, 11, 325-345. http://dx.doi.org/10.1016/S0002-8703(36)90417-9

[23] Pye, M., Quinn, A.C. and Cobbe, S.M. (1994) QT Interval Dispersion: A Non-Invasive Marker of Susceptibility to Arrhythmia in Patients with Sustained Ventricular Arrhythmias? British Heart Journal, 71, 511-514. http://dx.doi.org/10.1136/hrt.71.6.511 http://www.ncbi.nlm.nih.gov/pubmed/8043329

[24] Lang, R.M., Bierig, M., Devereux, R.B., Flachskampf, F.A., Foster, E., Pellikka, P.A., et al. (2005) Recommendations for Chamber Quantification: A Report from the American Society of Echocardiography's Guidelines and Standards Committee and the Chamber Quantification Writing Group, Developed in Conjunction with the European Association of Echocardiography, a Branch of the European Society of Cardiology. Journal of the American Society of Echocardiography, 18, 1440-1463. http://www.ncbi.nlm.nih.gov/pubmed/16376782

http://dx.doi.org/10.1016/j.echo.2005.10.005

[25] Devereux, R.B., Alonso, D.R., Lutas, E.M., Gottlieb, G.J., Campo, E., Sachs I., et al. (1986) Echocardiographic Assessment of Left Ventricular Hypertrophy: Comparison to Necropsy Findings. American Journal of Cardiology, 57, 450- 
458. http://www.ncbi.nlm.nih.gov/pubmed/2936235

[26] Gladwin, M.T., Sachdev, V., Jison, M.L., Shizukuda, Y., Plehn, J.F., Minter, K., et al. (2004) Pulmonary Hypertension as a Risk Factor for Death in Patients with Sickle Cell Disease. The New England Journal of Medicine, 350, 886-895. http://www.ncbi.nlm.nih.gov/pubmed/14985486 http://dx.doi.org/10.1056/NEJMoa035477

[27] Metivier, F., Marchais, S.J., Guerin, A.P., Pannier, B. and London, G.M. (2000) Pathophysiology of Anaemia: Focus on the Heart and Blood Vessels. Nephrology Dialysis Transplantation, 15, 14-18.

http://www.ncbi.nlm.nih.gov/pubmed/11032352 http://dx.doi.org/10.1093/oxfordjournals.ndt.a027970

[28] Aessopos, A., Deftereos, S., Farmakis, D., Corovesis, C., Tassiopoulos, S., Tsironi, M., et al. (2004) Cardiovascular Adaptation to Chronic Anemia in the Elderly: An Echocardiographic Study. Clinical \& Investigative Medicine, 27, 265273. http://www.ncbi.nlm.nih.gov/pubmed/15559863

[29] Kocharian, A., Rooyfard, M.D. and Aghanouri, R. (2003) Prolonged Dispersion of QT and QTc in Thalassemia Major Patients. Acta Medica Iranica, 41, 233-237. http://acta.tums.ac.ir/index.php/acta/article/view/2694.pdf

[30] Yaprak, I., Aksit, S., Oztürk, C., Bakiler, A.R., Dorak, C. and Turker, M. (1998) Left Ventricular Diastolic Abnormalities in Children with Beta-Thalassemia Major: A Doppler Echocardiographic Study. The Turkish Journal of Pediatrics, 40, 201-209. http://www.ncbi.nlm.nih.gov/pubmed/9677725

[31] Spirito, P., Lupi, G., Melevendi, C. and Vecchio, C. (1990) Restrictive Diastolic Abnormalities Identified by Doppler Echocardiography in Patients with Thalassemia Major. Circulation, 82, 88-94. http://dx.doi.org/10.1161/01.CIR.82.1.88 http://www.ncbi.nlm.nih.gov/pubmed/2364528

[32] Bosi, G., Crepaz, R., Gamberini, M.R., Fortini, M., Scarcia, S., Bonsante, E., et al. (2003) Left Ventricular Remodelling, and Systolic and Diastolic Function in Young Adults with Beta Thalassaemia Major: A Doppler Echocardiographic Assessment and Correlation with Haematological Data. Heart, 89, 762-766.

http://www.ncbi.nlm.nih.gov/pubmed/12807852 http://dx.doi.org/10.1136/heart.89.7.762

[33] Mandinov, L., Kaufmann, P., Brunner, F. and Hess, O.M. (1997) [Anemia and Heart Function]. Praxis (Bern 1994), 86, 1687-1692. http://www.ncbi.nlm.nih.gov/pubmed/9432693

[34] Akgül, F., Yalçin, F., Babayiğit, C., Seyfeli, E., Seydaliyeva, T. and Gali, E. (2006) Right Ventricular and Pulmonary Function in Sickle Cell Disease Patients with Pulmonary Hypertension. Pediatric Cardiology, 27, 440-446. http://www.ncbi.nlm.nih.gov/pubmed/16835804 http://dx.doi.org/10.1007/s00246-006-1257-8

[35] Sachdev, V., Machado, R.F., Shizukuda, Y., Rao, Y.N., Sidenko, S., Ernst, I., et al. (2007) Diastolic Dysfunction Is an Independent Risk Factor for Death in Patients with Sickle Cell Disease. Journal of the American College of Cardiology, 49, 472-479. http://www.ncbi.nlm.nih.gov/pubmed/17258093 http://dx.doi.org/10.1016/j.jacc.2006.09.038

[36] Gladwin, M.T., Schechter, A.N., Ognibene, F.P., Coles, W.A., Reiter, C.D., Schenke, W.H., et al. (2003) Divergent Nitric Oxide Bioavailability in Men and Women with Sickle Cell Disease. Circulation, 107, 271-278.

http://www.ncbi.nlm.nih.gov/pubmed/12538427 http://dx.doi.org/10.1161/01.CIR.0000044943.12533.A8

[37] Lin, G., Macdonald, R.L., Marton, L.S., Kowalczuk, A., Solenski, N.J. and Weir, B.K. (2001) Hemoglobin Increases Endothelin-1 in Endothelial Cells by Decreasing Nitric Oxide. Biochemical and Biophysical Research Communications, 280, 824-830. http://www.ncbi.nlm.nih.gov/pubmed/11162595 http://dx.doi.org/10.1006/bbrc.2000.4167

[38] Aessopos, A. and Farmakis, D. (2005) Pulmonary Hypertension in Beta-Thalassemia. Annals of the New York Academy of Sciences, 1054, 342-349. http://www.ncbi.nlm.nih.gov/pubmed/16339682 http://dx.doi.org/10.1196/annals.1345.041 